\title{
Gender, Perpetrator Attractiveness, and Ambivalent Sexism as Predictors of Victim Blaming, Minimization, and Subjective Fear in Stalking Incidents
}

\author{
Niwako Yamawaki, Jane Green, Marissa James, Tatyana Brenes S., Abena Yirenya-Tawiah, \\ Alice Nuo-Yi Wang \\ Department of Psychology, Brigham Young University, Provo, USA \\ Email: niwako_yamawaki@byu.edu
}

How to cite this paper: Yamawaki, N., Green, J., James, M., Brenes S., T., YirenyaTawiah, A., \& Wang, A. N.-Y. (2020). Gender, Perpetrator Attractiveness, and Ambivalent Sexism as Predictors of Victim Blaming, Minimization, and Subjective Fear in Stalking Incidents. Psychology, 11, 1675-1690. https://doi.org/10.4236/psych.2020.1111106

Received: October 3, 2020

Accepted: November 14, 2020

Published: November 17, 2020

Copyright $\odot 2020$ by author(s) and Scientific Research Publishing Inc. This work is licensed under the Creative Commons Attribution International License (CC BY 4.0).

http://creativecommons.org/licenses/by/4.0/

\begin{abstract}
The aim of this study was to examine how participant gender affected individuals' perceptions toward stalking and stalking victims. We also explored how the attractiveness of stalking perpetrators impacted perceptions of stalking along with the role of ambivalent sexism. A total of 120 undergraduate students in the research pool were randomly assigned to read one of two stalking scenarios that either portrayed the perpetrator as attractive or non-attractive. Participants completed related measures of victim blame attribution, stalking minimization, subjective fear, and ambivalent sexism. We performed a 2 $\times 2$ MANOVA, a follow up ANOVA, and a series of multiple regression analyses to test the hypotheses, which were supported. The results revealed that men were more likely to blame the victim, minimize the stalking incident, and feel less subjective fear for the victim than did women. We found that both hostile sexism and benevolent sexism were significant predictors of blaming the victim. Furthermore, hostile sexism was a significant predictor of minimizing the stalking incident and feeling less subjective fear for the victim. Possible explanations for the results and future research directions are discussed.
\end{abstract}

\section{Keywords}

Gender, Stalking, Victim Blaming, Minimization, Subjective Fear, Ambivalent Sexism, Attractiveness, Hostile Sexism, Benevolent Sexism

\section{Introduction}

According to the Bureau of Justice Statistics, stalking is a prevalent interpersonal 
phenomenon that can diminish one's sense of safety (Catalano, 2012). Researchers in the National Intimate Partner and Sexual Violence Survey (NISVS, 2010) discovered a life prevalence rate that estimated $16.2 \%$ of women and $5.2 \%$ of men will be stalking victims. Similarly, in the 2011 NISVS, researchers found that $15.2 \%$ of women and $5.7 \%$ of men have experienced stalking (Breiding et al., 2014). As defined by the legal operationalization of stalking, victims had to express fear regarding their experiences for their experiences to be classified as stalking. Many participants in these two surveys reported not only the feeling of fear but also the sense or worry that someone close to them could be harmed or killed by their stalker.

At the federal level, a stalker is currently defined as a person who conducts themselves in a way that attempts to cause emotional distress and/or potential physical harm to their target of conduct, and stalking behaviors include the intention to kill, injure, harass, or intimidate another person (Legal Information Institute, n.d.). Stalking behaviors also include consistent physical or visual proximity, unwanted communication, repeated harassment, and implied or direct threats (National Center for Injury Prevention and Control, 2003; Spitzberg, 2017). For stalking to be classified as a criminal behavior, the stalking victim must react to and recognize the stalking behaviors as crimes (Legal Information Institute, n.d.; Spitzberg, 2017). Additionally, the victim must report fear (e.g., victim's subjective fear) for the behaviors to be considered stalking by the federal stalking law. As such, $53 \%$ of states in the United States require that the stalking behavior make the average person fearful, and $27 \%$ of states in the United States require both the victim and an average person to feel fear (Bureau of Justice Statistics, 2009).

Moreover, before a stalking incident can make it to court, law enforcement must take a level of action regarding the stalking incident. Researchers have found that less than $40 \%$ of stalking victims report police action against their stalker (Bureau of Justice Statistics, 2009). Law enforcement actions that were taken included filing a report (55\%), speaking with or warning the stalker (32\%), or suggesting a protection order (20\%; Bureau of Justice Statistics, 2009). While the only action that can lead to court is an arrest, only $8 \%$ of stalking victims who reported their case resulted in an arrest of the stalking perpetrator (Bureau of Justice Statistics, 2009). However, the alarming scarcity of arrests does not correspond with the finding that more than $60 \%$ of these victims feared that the stalking perpetrator would harm them, their partner, or a family member. These victims also felt uncertainty of what would happen next, thought that the stalking might have an infinite duration, and feared death would result from the stalking behaviors they experienced (Bureau of Justice Statistics, 2009).

For the purpose of the current study, we examined how individuals blamed stalking victims, minimized stalking incidents, and felt subjective fear for stalking victims when the stalking perpetrator was either attractive or non-attractive. We also examined the role of ambivalent sexism. By examining both the attrac- 
tiveness of the stalking perpetrator and the ambivalent sexism of participants, we added to the scarce amount of research related to how individuals view stalking and examined how these variables impact the way individuals blame victims, minimize stalking, and feel subjective fear for victims.

\subsection{Gendered Perceptions and Experiences Related to Stalking}

Previous researchers have reported that women perceive stalking behaviors from male perpetrators to be more serious than stalking behaviors from female perpetrators (e.g., Finnegan \& Timmons Fritz, 2012; Scott et al., 2015; Sheridan \& Scott, 2010). Furthermore, women's experiences of being stalked appear to be disproportionately higher than that of men's, with women constituting two thirds of victims (Scott et al., 2018; Spitzberg, 2017). On the contrary, men tend to perceive stalking by women as less severe than they perceive stalking by men, and men comprise one third of victims (Owens, 2016; Schell \& Lanteigne, 2000; Scott et. al, 2018; Wigman, 2009). While previous researchers have suggested that men stalkers are more likely to be prosecuted compared to women stalkers (Hall, 1998; Purcell et al., 2001), more recent researchers have indicated that the majority of prosecutions against men arrested for stalking are dismissed or amended (Klein et al., 2009).

Researchers have also found that compared to men, women are more likely to blame stalking perpetrators and recognize intrusion or harassment as stalking (Haugaard \& Seri, 2003; Spitzberg et al., 2010; Yanowitz \& Yanowitz, 2012). Other researchers have found that men typically blame victims of stalking and minimize stalking incidents more than women (Dunlap et al., 2015; McKeon et al., 2015; Sinclair, 2012). In general, men tend to minimize the seriousness of stalking behavior (e.g., fail to recognize stalking behavior as dangerous; Hall, 1998; Purcell et al., 2001). Furthermore, men commonly see stalking behavior as a nonserious occurrence, while women view stalking behavior as serious (McKeon et al., 2015). Researchers have found that skepticism, traditional gender roles, and masculinization all relate to men's victim blaming and stalking behaviors (Haugaard \& Seri, 2003; Owens, 2017; Spitzberg et al., 2010; Yanowitz \& Yanowitz, 2012). These traits may also relate to how men minimize stalking behaviors.

In support of these gender discrepancies, researchers have indicated that in general, men report less emotional reactivity than women toward negative stimuli (Owens, 2016). Conversely, women feel more emotionally strained, threatened, and fearful of stalking compared to men (Davis et al., 2001; Magyarics et al., 2015; Ngo \& Paternoster, 2013). This disparity possibly developed from the contribution of traditional gender roles and masculinization to men's desire to fit ideal masculinity (Owens, 2017). However, there is still some concern for men as victims since their experiences are met with indifference, skepticism, derision by law enforcement, and ridicule from society (Hall, 1998; Purcell et al., 2001; Wigman, 2009). Furthermore, the legal operationalization of stalking centered on a victim's perception of fear, combined with fear existing as an emotional re- 
sponse that is typically socially accepted from women, may contribute to the fact that women are the majority of victims in stalking victimization studies. Therefore, we hypothesized that men would be more likely to blame the stalking victim, minimize the stalking incident, and feel less subjective fear for the stalking victim compared to women.

\subsection{Attractiveness and Stalking}

Attractiveness was an additional factor explored within this study. Individualism, which is prominent in Western countries, places blame on people who do not achieve the "thin ideal" as the result of their personal efforts and failures (Klaczynski et al., 2004). Researchers have found indications of an implicit bias toward unattractive individuals, which ultimately leads to stigmatization and discrimination (Robertson \& Vohora, 2008). Attractiveness presents prejudice, which is very prevalent in adult workspaces, and it has been found that individuals who are considered unattractive are often perceived as less preferable for employment than people who are considered attractive (Powroznik, 2016).

Considering blame, bias, and prejudice toward unattractive people in the United States, attractiveness may contribute to individuals' perceptions of stalking perpetrators and stalking victims. People tend to believe that the more physically fit an individual is, the more socially competent, intelligent, mentally healthy, and well-adjusted they are as well (Puhl et al., 2005). In fact, defendant attractiveness results in more favorable juror decisions in stalking situations and other crimes (Abwender \& Hough, 2001; Cannon, 2012). Therefore, individuals may perceive an attractive man pursuing a woman as an ordinary pursuit and perceive an unattractive man pursuing a woman as stalking. As a result, we explored how the attractiveness of the stalking perpetrator impacted how participants blamed the stalking victim, minimized the stalking incident, and felt subjective fear for the stalking victim.

\subsection{Ambivalent Sexism and Gender Role Traditionality Related to Stalking}

Sexism is a multidimensional construct in which sexist attitudes become automatic and lead to polarized messages about members of a target group (Glick \& Fiske, 1996). These attitudes consist of antagonistic viewpoints, defined as hostile sexism (e.g., women are incompetent at work) and sympathetic feelings toward women, defined as benevolent sexism (e.g., women must be protected; Dardenne et al., 2007; Wiener et al., 1997). These sexist ideologies are identified as ambivalent sexism since attitudes about women can be both hostile and benevolent (Glick \& Fiske, 1996).

Hostile sexism is defined as gender-based prejudice (Glick \& Fiske, 1996). Individuals high in hostile sexism have an attitude that expresses a sexual antipathy toward women (e.g., all women are terrible drivers) which restricts women through negative evaluations while preserving male dominance (Bragg, 2011; 
Glick \& Fiske, 1996; Yamawaki, 2007). In a more subtle and often unnoticed form, benevolent sexism invokes the general idea that women are inferior to men and thus need special treatment (Bragg, 2011; Yamawaki, 2007; Yamawaki et al., 2007). Such beliefs result in prosocial behaviors because of the idea that women must be protected by men (Bragg, 2011; Yamawaki el al., 2007). This subjectively positive lens restricts women's roles by solidifying traditional gender roles through stereotyping and justifying a power dominance (Glick \& Fiske, 1996; Yamawaki, 2007).

Furthermore, previous researchers have suggested that gender role traditionality significantly explains courtship behavior (Bridges, 1991; Simonson \& Subich, 1999; Yamawaki \& Tschaz, 2005). These researchers have found that dominance, sexual aggression, and "the ability to gain sexual access to reluctant women" by men are attitudes that are justified and expected by society (Bridges, 1991; Simonson \& Subich, 1999; Yamawaki \& Tschanz, 2005). In contrast, society expects women to be fragile, passive, submissive, and responsible for sexual activity. Thus, both women and men are restricted, or assigned roles, by gender through stereotyping and justifying a power dominance (Bridges, 1991; Glick \& Fiske, 1996; Simonson \& Subich, 1999; Yamawaki \& Tschaz, 2005), while both women and men hold sexist attitudes (Cassese \& Holman, 2019; Glick \& Fiske, 1996; Oswald et al., 2019). As such, we explored how participants' ambivalent sexism impacted how participants blamed the stalking victim, minimized the stalking incident, and felt subjective fear for the stalking victim.

\section{Method}

\subsection{Participants}

Participants in this study were 120 undergraduate students-69 females and 51 males-from the psychology department research pool at a large, private university in the Rocky Mountain area. They participated in this study in exchange for extra credit or in fulfillment of course requirements. The age of the participants ranged from 18 to $36(M=20.33 ; S D=2.36) ; 102$ participants $(85 \%)$ were single and $18(15 \%)$ were married. The race composition was White (106; 88.3\%), Latino/a (3; 2.5\%), Asian ( $3 ; 2.5 \%)$, Native American ( $1 ; 0.8 \%)$, and Other (7; $5.9 \%)$. All participants were informed of the purpose of this study. This study was approved by the Institutional Review Board at the university, and all participants were treated in accordance with the ethical guidelines of the American Psychological Association.

\subsection{Materials}

\section{Stalking Scenarios}

Brief, hypothetical stalking scenarios were created and used in this study. Participants were requested to read an alleged stalking case perpetrated by either an attractive or a non-attractive male pursuer. Participants were given the following instructions: "Imagine how the woman in the scenario may feel by a man who 
romantically pursued her. Please click the number that best describes your degree of agreement or disagreement with each statement." The scenarios used in this study were descriptions of stalkers' behaviors in convicted stalking cases. We used and/or modified such behavior to fit college students' lifestyles. The scenario was manipulated by the attractiveness of the perpetrator:

Rachel meets Adam at freshman orientation. Throughout the orientation Rachel begins to notice that Adam may be interested in her. Adam is [not] an attractive guy and some of her female group members have a crush on him [always ignored him]. Adam is confident, ambitious, self-assured, and an assertive "manly" man. Rachel is flattered, but she wants to focus on adjusting to her new college life. Later that week, Rachel notices that she and Adam have a class together. One day after class Adam approaches Rachel and asks her out on a date, but she refuses. A couple of days later Rachel finds a note from Adam on her car after work asking her to reconsider the date. She is surprised by the note because she did not know how he knew her car. Following the note, Adam begins to call her a couple of times a day. As the weeks go by, Rachel decides to skip class in order to avoid Adam. One night, he shows up to her door with a gift and lecture note saying that he missed her in class. Rachel was very surprised that Adam knew where she lives. Rachel confided with her friend about what is going on with Adam, so her friends asked Adam not to stalk her. Adam seemed very surprised and told them that he is not stalking her, but he is just pursuing her. He thinks that it is men's duty to initiate relationship, and women often pretend to be hard to get.

\section{Stalking Victim Blame Attribution Scale (SVBAS)}

To evaluate the blame attributed to the stalking victim by participants, the Stalking Victim Blame Attribution Scale (SVBAS) was created by modifying a measure by Yamawaki et al. (2009). This measure assessed respondents' perceptions of the stalking victim by placing blame on the victim herself. It consisted of six items: 1) Rachel has some fault in this incident, 2) Rachel should have communicated that she is not interested in a relationship with Adam, 3) Rachel unconsciously wants to be pursued by Adam, 4) Rachel has some responsibility for creating the situation, 5) Rachel should not engage in "hard to get" game, and 6) Rachel is making a big deal out of nothing. Responses to the questions on the SVBAS were assessed on a Likert-type scale that ranged from 1 "Strongly disagree" to 7 "Strongly agree." Higher scores reflected the endorsement of greater attributions of blame to the victim in the stalking scenario. The Cronbach's alpha for this scale was 0.80 .

\section{Stalking Minimization Scale (SMS)}

The Stalking Minimization Scale (SMS) measure was created for the purpose of this study. The SMS was designed to evaluate the degree to which alleged stalking behavior was minimized in the hypothetical scenarios. The SMS consisted of six items: 1) Adam's behavior causes Rachel to be fearful or experience 
personal distress, 2) This incident is a violation of Rachel's rights, 3) Adam's behavior constitutes stalking, 4) Adam's behavior necessitates police intervention, 5) This incident makes me concerned for Rachel's physical and psychological well-being, and 6) A criminal conviction is necessary for the resolution of this situation. The participants rated items on a 7-point Likert scale that ranged from 1 "Strongly disagree" to 7 "Strongly agree." All items were reverse scored and summed; thus, higher scores reflect attributions that minimized the seriousness of the stalking. The internal consistency estimate in the present study was 0.86 .

\section{Subjective Fear Scale (SFS)}

The Subjective Fear Scale (SFS) was recently developed and used in this study. The SFS evaluated respondents' own feelings of fear as if they were the victim. It contained four items: 1) If I were Rachel, I would be distressed because of Adam's behavior, 2) If I were Rachel, I would be fearful because of Adam's behavior, 3) If I were Rachel, I would feel threatened because of Adam's behavior, and 4) If I were Rachel, I would be frightened because of Adam's behavior. Participants rated their own feelings of fear on a Likert-type scale that ranged from 1 "Strongly disagree" to 7 "Strongly agree." Higher scores reflected the endorsement of greater attributions of blame to the victim in the stalking scenario. The Cronbach's alpha for this scale was 0.85 .

\section{Ambivalent Sexism Inventory (ASI)}

The Ambivalent Sexism Inventory (ASI) has been widely used and consists of 22 items with two subscales-Hostile Sexism (HS) and Benevolent Sexism (BS; Glick \& Fiske, 1996). Participants rated the items by using a 7-point Likert scale labeled 1 "Strongly disagree" to 7 "Strongly agree." One example of the items on the Hostile Sexism subscale is the following: "When women lose to men in fair competitions they typically complain about being discriminated against." An example of the items on the Benevolent Sexism subscale includes the following: "Women should be cherished and protected by men." Higher scores reflected greater levels of both hostile and benevolent sexism. The Cronbach's alphas in the present study for hostile sexism and benevolent sexism were 0.90 and 0.84 , respectively.

\section{Procedure}

Participants were undergraduate students who were enrolled in introductory psychology classes. Participants were recruited through the SONA system. The questionnaire and scenario were administered electronically via a Qualtrics webbased survey (Qualtrics.com), and only participants who gave their consent to participate were allowed to read an assigned scenario and complete the questionnaire. Participants were informed that the purpose of this study was to assess college students' perceptions about a man's romantic pursuit of a woman whom he met on campus. Participants were randomly assigned to one of the two scenarios (i.e., attractive vs. non-attractive male pursuer) and were asked to complete the SVBAS, SMS, SFS, ASI, and a demographic survey which asked for the following personal information: age, gender, marital status, race, and ethnicity. 
Participants who completed this study were compensated by receiving course credit for their participation.

\section{Results}

Effects of Attractiveness and Participants' Gender on Victim Blame Attribution, Minimization, and Subjective Feeling of Fear

To examine the effects of attractiveness of the stalker and participants' gender, a 2 (attractive vs. non-attractive) $\times 2$ (male and female) multivariate analysis of variance (MANOVA) was performed on the dependent variables-blaming, minimizing, and feeling of fear. This analysis showed a significant main effect of gender (Wilk's $\Lambda=0.80 ; F[3,113]=9.28, p<0.001$ ). However, there was no main effect of attractiveness (Wilk's $\Lambda=0.96 ; F[3,113]=1.14$, n.s.) nor significant interaction effect (Wilk's $\Lambda=0.96 ; F[3,113]=1.62$, n.s.). Analyses of variance (ANOVA) on each dependent variable were conducted to follow up on the MANOVA results. The results revealed that the male participants blamed the victim more $\left(F[1,119]=22.40, p<0.001 ; \mathrm{M}_{\text {male }}\left[\mathrm{SD}_{\text {male }}\right]=20.95[6.24] \mathrm{vs}\right.$. $\left.\mathrm{M}_{\text {female }}\left[\mathrm{SD}_{\text {female }}\right]=15.40[6.15]\right)$, minimized the alleged stalking incident more $(F$ $[1,119]=7.21, p<0.01 ; \mathrm{M}_{\text {male }}\left[\mathrm{SD}_{\text {male }}\right]=15.07$ [6.67] vs. $\mathrm{M}_{\text {female }}\left[\mathrm{SD}_{\text {female }}\right]=12.02$ [5.64]), and felt less fear for the victim in comparison to female participants ( $F$ $[1,119]=14.80, p<0.001 ; \mathrm{M}_{\text {male }}\left[\mathrm{SD}_{\text {male }}\right]=20.97[7.10]$ vs. $\mathrm{M}_{\text {female }}\left[\mathrm{SD}_{\text {female }}\right]=$ $26.72[7.93])$.

Predictive Roles of Ambivalent Sexism on Victim Blame Attribution, Minimization, and Subjective Feeling of Fear

To assess the predictive roles of ambivalent sexism on victim blame attribution, minimization, and subjective feeling of fear, a series of simultaneous multiple regression analyses were performed. The results of the regression analysis revealed that both hostile and benevolent sexism were significant predictors of victim blame attribution $[\beta=0.35, t(113)=4.16, p<0.001$ and $\beta=0.30, t(113)$ $=3.62, p<0.001$, respectively], explaining a significant proportion of variance in victim blame attribution $\left[F(2,111)=20.80, p<0.001, R^{2}=.27, R^{2}\right.$ adj $\left.=0.26\right]$. This result indicated that participants with higher hostile and benevolent sexism were more likely to blame the stalking victim. In terms of minimization of the stalking incident and subjective feeling of fear, the results of the multiple regression analyses indicated that hostile sexism was a significant predictor $[\beta=.33, t$ $(112)=3.59, p<0.001 ; \beta=-0.31, t(112)=-3.37, p<0.001$, respectively]. Thus, participants with higher hostile sexism tended to minimize the stalking incident more and felt less fear in the hypothetical scenario in comparison to those with lower hostile sexism. Benevolent sexism, however, was not a significant predictor of minimization and subjective feeling of fear $[\beta=0.06, t(112)=0.65$, n.s.; $\beta$ $=-0.12, t(112)=-1.25$, n.s., respectively].

\section{Discussion}

The purpose of this study was to examine individuals' differences in perceptions 
of stalking regarding attractive and non-attractive stalking perpetrators. This study allowed us to examine how individuals view stalkers based on the stalker's attractiveness and how individuals blame stalking victims, minimize stalking, and feel subjective fear for stalking victims. This study also helped us explore ambivalent sexism's predicting role. In the current study, we found that men and women differed in how they blamed victims, minimized stalking, and felt subjective fear for victims. We found no main effect of attractiveness or an interaction of participant gender and the attractiveness of the perpetrator. However, we did find significant results regarding ambivalent sexism.

We found that men blamed stalking victims and minimized stalking behaviors more than women did, and these findings have been previously noted (Dunlap, 2010; Dunlap et al., 2015; Lambert et al., 2013; McKeon et al., 2015; Sinclair, 2012). Furthermore, researchers have also found that women more readily perceive stalking behaviors and identify these behaviors as stalking compared to men (Chan \& Sheridan, 2017; Phillips et al., 2004). It is speculated that since more women are victimized by stalking (e.g., Breiding et al., 2014; Smith et al., 2015; Spitzberg \& Cupach, 2014), it may be easier for women to identify with the victim in a hypothetical scenario. As such, women may be better able to identify stalking behaviors and may be able to identify more with stalking victims compared to men. This is problematic when men are unlikely to identify stalking behaviors, as they may engage in stalking behaviors without recognizing their behaviors.

We also found that men felt less subjective fear for victims, and these findings have been supported by previous researchers (Englebrecht \& Reyns, 2011; Owens, 2016; Owens, 2017; Sheridan \& Lyndon, 2012). Ultimately, there is an overall difference in how feeling subjective fear for victims is both expressed and reported based on gender. These findings could be because men identify more with stalking perpetrators than with stalking victims (e.g., Dunlap et al., 2012; Scott et al., 2015) regardless of the gender of the perpetrator. These findings may also be explained by differing views regarding whether or not fear is felt by the stalking victim. Men tend to rate perpetrators guilty less frequently when the victim's fear is low (e.g., Dunlap et al., 2012). This signifies that, for men, the absence of fear felt by the victim from a stalking incident may perceive the stalking incident as less dangerous, less threatening, and less worrisome. Furthermore, women, compared to men, recognize that stalking victims can suffer from psychological pain (e.g., Miglietta \& Maran, 2017). Therefore, it may be evident that women, compared to men, would report higher levels of subjective fear because of their understanding that stalking can cause additional psychological pain rather than only physical pain. Women may also be more likely to express subjective fear for the stalking victim compared to men since women are more likely to be victimized.

Because of the differences in perceptions between men and women regarding blame, minimization, and subjective fear related to stalking, some men continue 
to pursue romantic relationships in a way that constitutes stalking. This behavior could possibly be explained by the overall gender differences that are present between women and men as aforementioned. It may also be because of ideology (e.g., men with a traditional ideology may view stalking as romantic instead of dangerous). Ambivalent sexism may also be another explanation. Men high in hostile sexism have a lack of empathy for women and may express that women deserve to be stalked. Similar to gender role ideology, men high in benevolent sexism may view pursuing another individual, specifically a woman, as a romantic behavior and claim that it is the "man's job" to pursue. Furthermore, men high in benevolent sexism may also not view stalking as dangerous or have the ability to view stalking behaviors as potentially life-threatening to the victim, enabling the mindset that stalking behaviors are appropriate.

Moreover, previous researchers have found that gender differences are related to violence against women in general (e.g., rape, domestic violence, sexual violence; as discussed in Powell \& Webster, 2018). As such, it is not atypical to find that men more commonly blame stalking victims, minimize stalking incidents, and feel less subjective fear for stalking victims. There are many possibilities as to why these findings are consistent in the literature. One such possibility is that women, compared to men, are more attentive to violence against women, which could be because women are more commonly victims of violence compared to men. It may also be because there are more data and research available related to women victims' experiences with violence (e.g., stalking) and women's attitudes and perceptions about stalking compared to men's.

Public stigma is also a possible explanation for gender differences. Linos (2009) explained that, since perpetrators of violence are commonly men, men who experience violence-such as sexual violence and stalking-may experience public stigma. Furthermore, men experiencing violence in general is a stigmatized issue (Christian et al., 2011). Men who experience violence may be stigmatized because of their identity as a victim and may be viewed as less of a man and weak by others. Public stigma of men experiencing violence (e.g., stalking) could be related to how and why men blame stalking victims more, minimize stalking incidents more, and feel less subjective fear for stalking victims compared to women. Therefore, public stigma could be one reason why men identify more with stalking perpetrators and less with stalking victims. Identifying more with a stalking perpetrator would be the "normal" reaction for men to have, and this reaction would be less detrimental toward a man's masculinity than would identifying as a stalking victim. Furthermore, men who have not been victims of stalking or gender violence may also view blaming victims, minimizing stalking, and feeling less subjective fear for victims as the "norm" for men.

We found no effect of perpetrator attractiveness on individuals' intentions to blame the victim, minimize the stalking, or feel subjective fear for the victim. We may not have found an effect on attractiveness of the perpetrator because of our sample. Our sample consisted of young, White college students, and these indi- 
viduals may not have contributed much attention to the attractiveness component of the scenario they read. These individuals may also have been more accepting of individuals, regardless of physical attributes. In turn, these factors may have led to no effect of the attractiveness of the perpetrator. It is recommended that other researchers examine potential main effects of perpetrator attractiveness within their research studies. Specifically, it is important to examine whether or not attractiveness plays a role in individuals' perceptions of stalking. As such, different manipulations of the attractiveness of the perpetrator is warranted to examine.

In the current study, we found that both hostile and benevolent sexism (i.e., ambivalent sexism) were significant predictors of victim blaming. Individuals who were higher in ambivalent sexism were more likely to blame stalking victims compared to individuals who were lower in ambivalent sexism. One researcher previously found that hostility toward women is linked to victim blaming (Yamawaki, 2007). One potential reason for these findings could be that, regardless of their gender, individuals higher in hostile sexism attribute more blame to stalking victims. It is also likely that hostile sexism could be related to how hostile sexists view female stalking victims, since hostile sexism consists of having antipathy toward women in general. Furthermore, benevolent sexism may be related to victim blaming since benevolent sexism is closely related to traditional gender roles (Glick \& Fiske, 1996; Hellmer et al., 2018). These findings may also represent that individuals higher in both benevolent sexism and traditional gender roles are more likely to blame women who experience violence, including stalking.

We further found that hostile sexism was a predictor of both minimizing the stalking incident and feeling subjective fear for stalking victims. Researchers have found that hostile sexism is related to the endorsement of sexist attitudes toward women (Miglietta \& Maran, 2017), violence against women (Yamawaki et al., 2009), and date rape (Yamawaki, 2007). Specifically, Yamawaki (2007) found that individuals high in hostile sexism minimized the seriousness of rape, and a similar conclusion can be made in relation to stalking. The current study's findings, which relate to Yamawaki's (2007) findings, may be explained by the less accepting attitude that individuals high in hostile sexism have toward women in general. Other reasons could include that individuals high in hostile sexism are more tolerant of violence against women and that they may hold stronger identities with perpetrators of violence, including stalking.

While hostile sexism predicted minimizing stalking and feeling subjective fear for stalking victims, benevolent sexism did not. Previous researchers found that individuals high in benevolent sexism viewed stalking as annoying but not actually dangerous toward victims (Miglietta \& Maran, 2017). However, for the current study, null findings could indicate that individuals view benevolent sexism as beneficial instead of detrimental to women. As such, individuals high in benevolent sexism hold views that women should be protected, try to establish 
that women should possess traditional gender roles, and may view stalking behavior toward women ambiguously. Because of the absence of these findings in the current study, we encourage future researchers to examine the role of benevolent sexism as a predictor of blaming stalking victims, minimizing stalking incidents, and feeling subjective fear for stalking victims.

Gender differences have been found to be related to sexism and hostile attitudes toward women in general (e.g., Powell \& Webster, 2018). Such findings can possibly be explained by the higher tendency of men who are high in hostile sexism to blame stalking victims. Reasons for this tendency could be that men with higher hostile sexism attitudes view women as incompetent, have a general antipathy toward women, and evaluate women negatively. Hostile sexists may also believe that women who are stalked are responsible for the stalking incident. As such, this belief could indicate that hostile sexists tend to believe in and accept stalking myths by thinking women deserve to be stalked. They may also think women behave in certain ways that seem like they are asking to be stalked.

We recommend more initiative and research regarding appropriately defining stalking with an encompassing, universal definition. While an appropriate definition is recommended, it is also important to address both the presence and absence of fearful feelings when defining stalking since both are crucial components. This is an important component moving forward with research regarding stalking since not all stalking victims fall into identical categories (i.e., some stalking victims feel fear while some do not). A universal definition encompassing both possibilities is warranted. Furthermore, we also recommend that future researchers work on intervention programs and conduct future research regarding the relationship between gender differences, ambivalent sexism, and stalking. It is pivotal to implement literature about stalking and gender differences and literature about stalking and ambivalent sexism. Researchers should provide literature that contains facts while debunking the myths about stalking. Specifically, this literature should educate individuals about both gender differences and ambivalent sexism. It is also noteworthy to continue examining the predicting role of ambivalent sexism and continue to examine more aspects of stalking perpetrator attractiveness.

There were some limitations for this study. In terms of our sample, only undergraduate students were recruited for participation. However, many college students are young, and in our specific sample of young college students, participants fell in the age range in which stalking most commonly occurs (i.e., 18 - 29 years old; Tjaden \& Thoennes, 2000). Therefore, many participants in this study were likely to be familiar with, have previously experienced, or knew of someone who had experienced stalking, which allowed us to recruit individuals who were more likely to be aware of stalking and understand the concept of stalking. Another limitation of this study was that most participants were White. We recommend future researchers obtain a more representative sample regarding both race and ethnicity to promote generalizability of the findings. It is recommended that fu- 
ture researchers examine how the race of participants impact blaming stalking victims, minimizing stalking incidents, and feeling subjective fear for stalking victims.

\section{Conflicts of Interest}

The authors declare no conflicts of interest regarding the publication of this paper.

\section{References}

Abwender, D. A., \& Hough, K. (2001). Interactive Effects of Characteristics of Defendant and Mock Juror on U.S. Participants' Judgment and Sentencing Recommendations. The Journal of Social Psychology, 141, 603-615. https://doi.org/10.1080/00224540109600574

Bragg, C. B. (2011). Ambivalent Sexism and Traditional Gender Roles as Predictors of Performance Evaluation Bias. Master's Thesis, Provo, UT: Brigham Young University.

Breiding, M. J., Smith, S. G., Basile, K. C., Walters, M. L., Chen, J., \& Merrick, M. T. (2014). Prevalence and Characteristics of Sexual Violence, Stalking, and Intimate Partner Violence Victimization-National Intimate Partner and Sexual Violence Survey, United States, 2011. American Journal of Public Health, 63, 1-18.

Bridges, J. S. (1991). Perceptions of Date and Stranger Rape: A Difference in Sex Role Expectations and Rape-Supportive Beliefs. Sex Roles, 24, 291-307.

https://doi.org/10.1007/BF00288303

Bureau of Justice Statistics (2009). Stalking Victimization in the United States. National Crime Victimization Survey. https://www.justice.gov/sites/default/files/ovw/legacy/2012/08/15/bjs-stalking-rpt.pdf

Cannon, A. (2012). Examining the Role of Defendant Attractiveness on Juror Decisions for Crimes Relating to Stalking, Burglary, and Murder. Undergraduate Project, Manchester Metropolitan University, Manchester Metropolitan University's Research Repository.

Cassese, E. C., \& Holman, M. R. (2019). Playing the Woman Card: Ambivalent Sexism in the 2016 US Presidential Race. Political Psychology, 40, 55-74.

https://doi.org/10.1111/pops.12492

Catalano, S. (2012). Stalking Victims in the United States-Revised. Washington DC: U.S. Department of Justice. https://www.bjs.gov/content/pub/pdf/svus rev.pdf

Chan, H. C. O., \& Sheridan, L. (2017). Is This Stalking? Perceptions of Stalking Behavior among Young Male and Female Adults in Hong Kong and Mainland China. Journal of Interpersonal Violence, 35, 3710-3734. https://doi.org/10.1177/0886260517711180

Christian, M., Safari, O., Ramazani, P., Burnham, G., \& Glass, N. (2011). Sexual and Gender Based Violence against Men in the Democratic Republic of Congo: Effects on Survivors, Their Families and the Community. Medicine, Conflict and Survival, 27, 227-246. https://doi.org/10.1080/13623699.2011.645144

Dardenne, B., Dumont, M., \& Bollier, T. (2007). Insidious Dangers of Benevolent Sexism: Consequences for Women's Performance. Journal of Personality and Social Psychology, 93, 764-779. https://doi.org/10.1037/0022-3514.93.5.764

Davis, K. E., Frieze, I. H., \& Maiuro, R. D. (2001). Stalking: Perspectives on Victims and Perpetrators. Berlin: Springer Publishing.

Dunlap, E. E. (2010). Stalking Myth Acceptance: An Investigation of Attitudinal Con- 
structs Associated with Gender Differences in Judgments of Intimate Stalking. Doctoral Dissertation, Lexington, KY: University of Kentucky.

Dunlap, E. E., Hodell, E. C., Golding, J. M., \& Wasarhaley, N. E. (2012). Mock Jurors' perception of Stalking: The Impact of Gender and Expressed Fear. Sex Roles, 66, 405-417. https://doi.org/10.1007/s11199-011-9970-Z

Dunlap, E. E., Lynch, K. R., Jewell, J. A., Wasarhaley, N. E., \& Golding, J. M. (2015). Participant Gender, Stalking Myth Acceptance, and Gender Role Stereotyping in Perceptions of Intimate Partner Stalking: A Structural Equation Modeling Approach. Psychology, Crime \& Law, 21, 234-253. https://doi.org/10.1080/1068316X.2014.951648

Englebrecht, C. M., \& Reyns, B. W. (2011). Gender Differences in Acknowledgment of Stalking Victimization: Results from the NCVS Stalking Supplement. Violence and Victims, 26, 560-579. https://doi.org/10.1891/0886-6708.26.5.560

Finnegan, H. A., \& Timmons Fritz, P. A. (2012). Differential Effects of Gender on Perceptions of Stalking and Harassment Behavior. Violence and Victims, 27, 895-910. https://doi.org/10.1891/0886-6708.27.6.895

Glick, P., \& Fiske, S. T. (1996). The Ambivalent Sexism Inventory: Differentiating Hostile and Benevolent Sexism. Journal of Personality and Social Psychology, 70, 491-512. https://doi.org/10.1037/0022-3514.70.3.491

Hall, D. M. (1998). The Victims of Stalking. In J. R. Maloy (Ed.), The Psychology of Stalking (pp. 113-137). Cambridge, MA: Academic Press. https://doi.org/10.1016/B978-012490560-3/50025-6

Haugaard, J. J., \& Seri, L. G. (2003). Stalking and Other Forms of Intrusive Contact after the Dissolution of Adolescent Dating or Romantic Relationships. Violence and Victims, 18, 279-297. https://doi.org/10.1891/vivi.2003.18.3.279

Hellmer, K., Stenson, J. T., \& Jylhä, K. M. (2018). What's (Not) Underpinning Ambivalent Sexism? Revisiting the Roles of Ideology, Religiosity, Personality, Demographics, and Men's Facial Hair in Explaining Hostile and Benevolent Sexism. Personality and Individual Differences, 122, 29-37. https://doi.org/10.1016/j.paid.2017.10.001

Klaczynski, P. A., Goold, K. W., \& Mudry, J. J. (2004). Culture, Obesity Stereotypes, Self-Esteem, and the "Thin Ideal": A Social Identity Perspective. Journal of Youth and Adolescence, 33, 307-317. https://doi.org/10.1023/B:JOYO.0000032639.71472.19

Klein, A., Salomon, A., Huntington, N., Dubois, J., \& Lang, D. (2009). Statewide Study of Stalking and Its Criminal Justice Response. Washington DC: U.S. Department of Justice. https://www.ncjrs.gov/pdffiles1/nij/grants/228354.pdf https://doi.org/10.1037/e619592009-001

Lambert, E. G., Smith, B., Geistman, J., Cluse-Tolar, T., \& Jiang, S. (2013). Do Men and Women Differ in Their Perceptions of Stalking: An Exploratory Study among College Students. Violence and Victims, 28, 195-209. https://doi.org/10.1891/0886-6708.09-201

Legal Information Institute (n.d.). Chapter 110A. Domestic Violence and Stalking: Section 2261. Stalking. https://www.law.cornell.edu/uscode/text/18/2261A

Linos, N. (2009). Rethinking Gender-Based Violence during War: Is Violence against Civilian Men a Problem Worth Addressing? Social Science and Medicine, 68, 1548-1551. https://doi.org/10.1016/j.socscimed.2009.02.001

Magyarics, C. L., Lynch, K. R., Golding, J. M., \& Lippert, A. (2015). The Impact of Frequency of Behavior and Type of Contact on Judgments Involving a Criminal Stalking Case. Law and Human Behavior, 39, 602-613. https://doi.org/10.1037/lhb0000151

McKeon, B., McEwan, T. E., \& Luebbers, S. (2015). “It’s Not Really Stalking If You Know the Person": Measuring Community Attitudes That Normalize, Justify and Minimise 
Stalking. Psychiatry, Psychology and Law, 22, 291-306. https://doi.org/10.1080/13218719.2014.945637

Miglietta, A., \& Maran, D. A. (2017). Gender, Sexism and the Social Representation of Stalking: What Makes the Difference? Psychology of Violence, 7, 563-573. https://doi.org/10.1037/vio0000070

National Center for Injury Prevention and Control (2003). Costs of Intimate Partner Violence against Women in the United States. https://www.cdc.gov/violenceprevention/pub/IPV cost.html

Ngo, F. T., \& Paternoster, R. (2013). Stalking, Gender and Coping: A Partial Test of Broidy and Agnew's Gender/General Strain Theory Hypothesis. Victims and Offenders, 8, 94-117. https://doi.org/10.1080/15564886.2012.749122

Oswald, D. L., Baalbaki, M., \& Kirkman, M. (2019). Experiences with Benevolent Sexism: Scale Development and Associations with Women's Well-Being. Sex Roles, 80, 362-380. https://doi.org/10.1007/s11199-018-0933-5

Owens, J. G. (2016). Why Definitions Matter: Stalking Victimization in the United States. Journal of Interpersonal Violence, 31, 2196-2226.

https://doi.org/10.1177/0886260515573577

Owens, J. G. (2017). A Gender-Biased Definition: Unintended Impacts of the Fear Requirement in Stalking Victimization. Crime \& Delinquency, 63, 1339-1362. https://doi.org/10.1177/0011128715615883

Phillips, L., Quirk, R., Rosenfeld, B., \& O'Connor, M. (2004). Is It Stalking? Perceptions of Stalking among College Undergraduates. Criminal Justice and Behavior, 31, 73-96. https://doi.org/10.1177/0093854803259251

Powell, A., \& Webster, K. (2018). Cultures of Gendered Violence: An Integrative Review of Measures of Attitudinal Support for Violence against Women. Australian and New Zealand Journal of Criminology, 51, 40-57. https://doi.org/10.1177/0004865816675669

Powroznik, K. M. (2016). Healthism and Weight-Based Discrimination. Work and Occupations, 44, 139-170. https://doi.org/10.1177/0730888416682576

Puhl, R. M., Schwartz, M. B., \& Brownell, K. D. (2005). Impact of Perceived Consensus on Stereotypes about Obese People: A New Approach for Reducing Bias. Health Psychology, 24, 517-525. https://doi.org/10.1037/0278-6133.24.5.517

Purcell, R., Pathé, M., \& Mullen, P. E. (2001). A Study of Women Who Stalk. The American Journal of Psychiatry, 158, 2056-2060. https://doi.org/10.1176/appi.ajp.158.12.2056

Robertson, N., \& Vohora, R. (2008). Fitness vs. Fatness: Implicit Bias towards Obesity among Fitness Professionals and Regular Exercisers. Psychology of Sport and Exercise, 9, 547-557. https://doi.org/10.1016/j.psychsport.2007.06.002

Schell, B. H., \& Lanteigne, N. M. (2000). Stalking, Harassment, and Murder in the Workplace: Guidelines for Protection and Prevention. Quorum Books.

Scott, A. J., Duff, S. C., Sheridan, L., \& Rajakaruna, N. (2018). The Influence of Contextual Information Regarding the Breakdown of Relationships and Perpetrator-Target Sex Composition on Perceptions of Relational Stalking. Psychology, Crime \& Law, 25, 364 380. https://doi.org/10.1080/1068316X.2018.1529231

Scott, A. J., Rajakaruna, N., Sheridan, L., \& Gavin, J. (2015). International Perceptions of Relational Stalking: The Influence of Prior Relationship, Perpetrator Sex, Target Sex, and Participant Sex. Journal of Interpersonal Violence, 30, 3308-3323. https://doi.org/10.1177/0886260514555012

Sheridan, L., \& Lyndon, A. E. (2012). The Influence of Prior Relationship, Gender, and Fear on the Consequences of Stalking Victimization. Sex Roles, 66, 340-350. 
https://doi.org/10.1007/s11199-010-9889-9

Sheridan, L., \& Scott, A. J. (2010). Perceptions of Harm: Verbal versus Physical Abuse in Stalking Scenarios. Criminal Justice and Behavior, 37, 400-416. https://doi.org/10.1177/0093854809359743

Simonson, K., \& Subich, L. M. (1999). Rape Perceptions as a Function of Gender-Role Traditionality and Victim-Perpetrator Association. Sex Roles, 40, 617-634. https://doi.org/10.1023/A:1018844231555

Sinclair, H. C. (2012). Stalking Myth-Attributions: Examining the Role of Individual and Contextual Variables on Attributions in Unwanted Pursuit Scenarios. Sex Roles, 66, 378-391. https://doi.org/10.1007/s11199-010-9853-8

Smith, S. G., Zhang, X., Basile, K. C., Merrick, M. T., Wang, J., Kresnow, M., \& Chen, J. (2015). The National Intimate Partner and Sexual Violence Survey: 2015 Data BriefUpdated Release. National Center for Injury Prevention and Control and Centers for Disease Control and Prevention.

https://www.cdc.gov/violenceprevention/pdf/2015data-brief508.pdf

Spitzberg, B. H. (2017). Acknowledgment of Unwanted Pursuit, Threats, Assault, and Stalking in a College Population. Psychology of Violence, 7, 265-275.

https://doi.org/10.1037/a0040205

Spitzberg, B. H., \& Cupach, W. R. (2014). The Dark Side of Relationship Pursuit: From Attraction to Obsession to Stalking (2nd ed.). Abingdon-on-Thames: Routledge. https://doi.org/10.4324/9780203805916

Spitzberg, B. H., Cupach, W. R., \& Ciceraro, L. D. L. (2010). Sex Differences in Stalking and Obsessive Relational Intrusion: Two Meta-Analyses. Partner Abuse, 1, 259-285. https://doi.org/10.1891/1946-6560.1.3.259

Tjaden, P., \& Thoennes, N. (2000). The Role of Stalking in Domestic Violence Crime Reports Generated by the Colorado Springs Police Department. Violence and Victims, 15, 427-441. https://doi.org/10.1891/0886-6708.15.4.427

Wiener, R. L., Hurt, L., Russell, B., Mannen, K., \& Gasper, C. (1997). Perceptions of Sexual Harassment: The Effects of Gender, Legal Standard, and Ambivalent Sexism. Law and Human Behavior, 21, 71-93. https://doi.org/10.1023/A:1024818110678

Wigman, S. A. (2009). Male Victims of Former-Intimate Stalking: A Selected Review. International Journal of Men's Health, 8, 101-115. https://doi.org/10.3149/jmh.0802.101

Yamawaki, N. (2007). Rape Perception and the Function of Ambivalent Sexism and GenderRole Traditionality. Journal of Interpersonal Violence, 22, 406-423. https://doi.org/10.1177/0886260506297210

Yamawaki, N., \& Tschanz, B. T. (2005). Rape Perception Differences between Japanese and American College Students: On the Mediating Influence of Gender Role Traditionality. Sex Roles, 52, 379-392. https://doi.org/10.1007/s11199-005-2680-7

Yamawaki, N., Darby, R., \& Queiroz, A. (2007). The Moderating Role of Ambivalent Sexism: The Influence of Power Status on Perception of Rape Victim and Rapist. The Journal of Social Psychology, 147, 41-56. https://doi.org/10.3200/SOCP.147.1.41-56

Yamawaki, N., Ostenson, J., \& Brown, C. R. (2009). The Functions of Gender Role Traditionality, Ambivalent Sexism, Injury, and Frequency of Assault on Domestic Violence Perception: A Study between Japanese and American College Students. Violence against Women, 15, 1126-1142. https://doi.org/10.1177/1077801209340758

Yanowitz, K. L., \& Yanowitz, J. L. (2012). The Role of Gender in the Generation of Stalking Scripts. Sex Roles, 66, 366-377. https://doi.org/10.1007/s11199-010-9867-2 